\title{
Una tipología de casos para enseñar el modelo de evolución por selección natural
}

\author{
A typology of cases to teach the model of \\ evolution by natural selection
}

DOI: $10.7203 / D C E S .34 .12056$

\author{
Leonardo González Galli \\ Consejo Nacional de Investigaciones Científicas y Técnicas (CONICET), leomgalli@gmail.com \\ ORCID iD: http://orcid.org/0000-0002-0713-164X
}

\begin{abstract}
Elsa Meinardi
Instituto de Investigaciones CeFIEC (Facultad de Ciencias Exactas y Naturales, Universidad de Buenos Aires), emeinardi@gmail.com
\end{abstract}

Gastón Pérez

Instituto de Investigaciones CeFIEC (Facultad de Ciencias Exactas y Naturales, Universidad de Buenos Aires), gastonperezbio@gmail.com

\begin{abstract}
RESUMEN: La enseñanza de todo contenido requiere utilizar casos o ejemplos concretos que sirvan de problemas que den sentido a la construcción de modelos cercanos a los científicos. Existen diversos criterios para la selección de dichos casos. En este trabajo se presentan los fundamentos de una propuesta para la selección de casos para la enseñanza del modelo de evolución por selección natural. Esta propuesta se basa en la interacción entre dichos casos y las concepciones y obstáculos epistemológicos de los estudiantes. Cada categoría de casos propuesta se define por las concepciones y obstáculos cuya explicitación y revisión facilita. Se sugiere también que la toma de conciencia sobre esas concepciones y obstáculos es una condición necesaria el aprendizaje tal como se lo entiende desde el marco teórico de la modelización.
\end{abstract}

Palabras Clave: enseñanza de la biología evolutiva, casos, concepciones, obstáculos epistemológicos.

ABSTRACT: The teaching of all content requires using specific cases or examples as problems that give meaning to the construction of nearby scientific models. There are several criteria for the selection of such cases. In this paper we present the fundamentals of a proposal for the selection of cases for the teaching of the model of evolution by natural selection. This proposal is based on the interaction between these cases and the epistemological conceptions and obstacles of the students. Each category of cases proposed here is defined by the concepts and obstacles whose explanation and revision facilitates. It is also suggested that the awareness of these conceptions and obstacles is a necessary condition for learning as it is understood from the theoretical framework of modeling.

KEYWORDS: evolutionary biology teaching, cases, conceptions, epistemological obstacles.

Fecha de recepción: febrero de 2018

Fecha de aceptación: julio de 2018

Este trabajo ha sido financiado por el Consejo Nacional de Investigaciones Científicas y Técnicas de Argentina y por la Universidad de Buenos Aires. 


\section{INTRODUCCIÓN}

Este trabajo se relaciona con la enseñanza y el aprendizaje del que puede considerarse el principal modelo de la biología evolutiva: el modelo de evolución por selección natural (MESN) (Dupré, 2006; González Galli y Meinardi, 2013). Se trata de un contenido que resulta central para la formación ciudadana pero cuyo aprendizaje, según muestran numerosos estudios, resulta extremadamente dificultoso (Kampourakis, 2014; Rosengren, 2012).

Resulta evidente que para enseñar un contenido dado es necesario recurrir a casos o ejemplos concretos. Es menos claro, sin embargo, qué criterios serían adecuados para seleccionar esos casos. Tal vez, el criterio más citado sea el de cercanía y relevancia del caso en relación con la vida cotidiana del estudiante (Sanmartí, 2002). Este criterio se fundamenta en el efecto motivador que tendrían dichos casos, y se relaciona con el objetivo -asociado a la llamada alfabetización científica- de formar ciudadanos críticos y autónomos (Fourez 2005; Meinardi, 2010; Sanmartí, 2002). En la misma línea, se recomienda tratar casos relacionados con las "prácticas sociales de referencia” (Astolfi, 2001). En la práctica educativa, sin embargo, las razones para la selección de un caso suelen ser menos pertinentes. Así, muchos ejemplos clásicos se utilizan principalmente por una cuestión de tradición; simplemente porque hace décadas que se repiten, principalmente en los libros de texto. Esto es claro en el caso de la teoría de la evolución, en cuya enseñanza nunca faltan los casos del "melanismo industrial” y del largo del cuello de la jirafa. En relación con la enseñanza de la teoría de la evolución, específicamente, existen unas pocas propuestas para la selección de casos (ver, por ejemplo, White et al., 2013; Zimmer, 2008) y ninguna comparable a la que aquí ofrecemos. Solo Kalinowsky et al. (2013) realizan una propuesta parcialmente coincidente con la nuestra, pero -entre otras importantes diferencias- en dicha propuesta no se ofrece un análisis detallado en términos de concepciones y obstáculos, tal como hacemos aquí. En este trabajo nos proponemos ofrecer otros criterios, anclados en análisis didácticos, para la selección de casos para enseñar el MESN. El criterio para la selección de casos que aquí ofrecemos se centra entonces en la relación entre dichos casos y las concepciones de los estudiantes. Desde el marco teórico de la modelización (Gómez, 2009) que adoptamos, se entiende que la principal función de dichas concepciones es servir de punto de partida para la construcción de modelos más cercanos a los científicos. Este proceso requiere, a su vez, que los estudiantes tomen conciencia de las concepciones en que basan sus razonamientos.

Nuestro objetivo es, entonces, proponer y fundamentar una tipología de casos que resulte útil para que los estudiantes expliciten sus concepciones sobre la evolución biológica, así como los obstáculos epistemológicos subyacentes. Más específicamente, buscamos la explicitación de concepciones y obstáculos que puedan dificultar el aprendizaje del modelo de evolución por selección natural (MESN). Partimos de la hipótesis según la cual la discusión de casos, que por sus particularidades impliquen poner en discusión ciertas concepciones y obstáculos de los estudiantes, facilitará la toma de conciencia y la regulación consciente e intencional (metacognición) de dichos modos de pensamiento.

\section{MARCOS TEÓRICOS}

Existe un fuerte consenso en relación con la necesidad de enseñar teniendo en cuenta las concepciones de los estudiantes (De Vecchi y Giordan, 2006; Meinardi, 2010; Sanmartí, 2002). En general, se acuerda además en la necesidad de que dichas concepciones sean explicitadas. Desde enfoques teóricos cercanos al modelo de cambio conceptual, esta explicitación será un paso necesario para la "desestabilización” y posterior reemplazo de las concepciones erróneas (Posner et al., 1988; Strike y Posner, 1992). Desde otros marcos teóricos, esta explicitación también es importante, aunque el objetivo de largo plazo no sea la eliminación y reemplazo de esas concepciones (Schnotz, Vosniadou y Carretero, 2006). En nuestro caso, partimos de un particular modo de entender la naturaleza de las concepciones de las y los estudiantes, y su rol en el proceso 
de aprendizaje, basado en el concepto de obstáculo epistemológico (Astolfi, 2001; González Galli y Meinardi, 2016). De acuerdo con este enfoque, podemos concebir que, en relación con "lo que el alumno ya sabe”, existe un continuo desde las concepciones más específicas y explícitas hasta las más generales e implícitas. Por ejemplo, en el caso de la evolución por selección natural, la idea de que "las bacterias mutan para hacerse resistentes al antibiótico" estaría en el extremo más específico y explícito de este continuo; es lo que el estudiante dice sobre un caso particular. Pero se puede inferir que dicha idea se basa en varias concepciones, más generales y menos explícitas, como, por ejemplo, aquella según la cual los organismos (individuales) tienen la capacidad de modificarse en sentido adaptativo y aquella según la cual esos cambios adaptativos luego son heredados por la descendencia (González Galli y Meinardi, 2015). Estas concepciones son más generales; el estudiante las aplica tanto al caso de las bacterias como al de, por ejemplo, la evolución del pelaje tupido en los zorros árticos. Pero aún es posible interpretar estas ideas como la expresión de concepciones más generales aún como, por ejemplo, el finalismo, esto es, la idea según la cual todos los procesos biológicos están dirigidos a un fin. El finalismo constituye un modo de pensar implícito y muy general que el estudiante puede aplicar tanto a la evolución como a, por ejemplo, un proceso fisiológico. A estas últimas concepciones, las más generales e implícitas, cuando entran en conflicto con los modelos a enseñar, las calificamos de obstáculos. La decisión en relación con cuándo una concepción es lo suficientemente general como para ser considerada un obstáculo está ligada al contexto, en el sentido de que depende de cómo de hecho funciona dicha concepción en la "ecología conceptual” del estudiante. Desde esta perspectiva, se sugiere la necesidad de trabajar sobre los obstáculos y no limitarse a operar sobre las concepciones más superficiales (Camilloni, 2001). Por otro lado, se asume que los obstáculos, debido a su importante función cognitiva, nunca desaparecen (Astolfi, 2001). Ponemos entonces el énfasis en el desarrollo de la capacidad de regular conscientemente la aparición de los obstáculos según el contexto (Peterfalvi, 2001). Estas capacidades se relacionan con la metacognición, un conjunto de habilidades cuya importancia crucial en el aprendizaje de las ciencias está ampliamente reconocida (Campanario, 2000; Zohar y Dori, 2012), por lo que hablamos del desarrollo de una capacidad de "vigilancia metacognitiva" sobre los obstáculos. Otra característica de los obstáculos que es importante señalar aquí es su “ambigüedad”. Con este término Astolfi (1999) se refiere al hecho de que si bien el obstáculo es una herramienta necesaria para la construcción de modelos es también, al mismo tiempo, una fuente de errores. Así, relación con el aprendizaje buscado el obstáculo es a la vez un factor negativo y positivo: permite a la vez que limita y sesga el aprendizaje. Este trabajo sobre los obstáculos requiere ser complementado con otro que favorezca la construcción de nuevos modelos. En este sentido, desde el marco teórico de la modelización, la enseñanza de las ciencias supone partir de la interpretación y construcción de fenómenos relevantes para llegar, finalmente, a alguna versión escolar del modelo a enseñar (Gómez, 2009). Estas primeras construcciones estarán inevitablemente basadas en las concepciones y obstáculos iniciales de los estudiantes (aquí vemos el mencionado aspecto positivo del obstáculo). Este proceso requiere discutir y argumentar a partir de preguntasproblema construidas en base al análisis de casos concretos. Una vez construida por parte de los y las estudiantes una versión básica del modelo científico es necesario complejizar dicho modelo y ampliar su campo de aplicación más allá de los ejemplos utilizados inicialmente. La introducción de nuevos casos de complejidad creciente permitirá así revisar y reformular la primera versión del modelo, de modo de dar lugar a la (re)construcción de una versión posterior más sofisticada. Se trata del "aprendizaje en espiral”, del alcance de distintos “niveles de formulación” (Astolfi, 2002, 2001) o de concebir una "hipótesis de progresión” (García, 1994). En este sentido, estas categorías (los tipos de casos que detallamos en la siguiente sección), tal como las presentamos, suponen un orden aproximado de complejidad creciente. Sin embargo, la complejidad efectiva dependerá de los conocimientos previos de los estudiantes, de modo que un mismo caso será menos complejo para una estudiante que ya ha construido un modelo robusto de evolución, o que esté familiarizado con ese ejemplo, que para uno que dispone de un modelo muy precario o que enfrente por primera vez 
el ejemplo en cuestión. Así, desde los tres marcos teóricos reseñados (obstáculos epistemológicos, metacognición y modelización) resulta necesario proponer actividades que faciliten la explicitación y revisión consciente y crítica de las concepciones de los y las estudiantes.

\section{UNA TIPOLOGÍA DE CASOS PARA ENSEÑAR EL MODELO DE EVOLUCIÓN POR SELECCIÓN NATURAL}

Para proponer estas categorías de casos nos basamos en un análisis teórico-epistemológico del MESN que permite identificar algunos “nudos de dificultad” (Ayala y Arp, 2010). Asumimos que es probable que las cuestiones que resultan problemáticas y poco claras en la propia biología no resulten claras para los estudiantes. También nos basamos en las investigaciones sobre las concepciones y obstáculos en relación con el aprendizaje del MESN (por ejemplo, Bishop y Anderson, 1990; González Galli y Meinardi, 2017, 2015, 2011; Jiménez, 1993), así como en nuestra experiencia como docentes en distintos niveles educativos.

Proponemos seis categorías de casos que pretenden tener dos virtudes didácticas: (1) favorecer la explicitación y revisión de ciertas concepciones de los estudiantes y de algunos de los obstáculos subyacentes y (2) propiciar la revisión, extensión y complejización de una versión básica del MESN. A continuación, describimos cada categoría e indicamos qué concepciones se podrían explicitar y discutir a partir de cada una. También hacemos referencia al "contrapunto conceptual" de estas concepciones y obstáculos, esto es, el componente del MESN con el que dichos modos de pensar entran en conflicto. En el Cuadro 1 ofrecemos un ejemplo concreto para cada categoría y en el Cuadro 2 esbozamos un análisis en relación con los posibles obstáculos subyacentes.

Categoría 1. Origen de un rasgo morfológico o fisiológico simple que implica una ventaja en relación con la supervivencia del individuo

En términos del MESN, con "simple” nos referimos a que resulta concebible que la variante seleccionada pueda surgir como consecuencia de un único cambio genético (mutación) a partir del estado ancestral. Esta categoría incluye casos análogos a los típicamente usados para la enseñanza del tema, tales como el del "melanismo industrial". Estos casos resultan relativamente sencillos de explicar para quienes han construido una versión básica del MESN, por lo que, eventualmente, las únicas concepciones que salen a la luz en su discusión son aquellas típicas de quienes no han recibido instrucción formal sobre el tema. Estas son también las concepciones con más frecuencia reportadas en la investigación. Las principales serían: (1a) transformación individual en sentido adaptativo en respuesta a la necesidad impuesta por el ambiente, (1b) nacimiento de crías “adaptadas” y (1c) herencia de los caracteres adquiridos (Bardapurkar, 2008; González Galli y Meinardi,2015; Jiménez, 1991). En cuanto al contrapunto conceptual solo caben mencionar los conceptos nucleares del MESN: la variación individual heredable y aleatoria, el impacto de esas variaciones en las probabilidades de supervivencia y reproducción y el cambio en la proporción de las variantes en la población a través de las generaciones (Futuyma, 2009).

Categoría 2. Origen de un rasgo morfológico o fisiológico simple que implica una ventaja en relación con el apareamiento (selección sexual)

Estos casos son bien conocidos, y es frecuente que los estudiantes propongan hipótesis cercanas a las aceptadas en la ciencia, por ejemplo, en términos de que "las hembras prefieren aparearse con los machos más vistosos”. Sin embargo, creemos que rara vez se capitaliza el potencial didáctico de estos ejemplos. Lo particular del caso es que se trata de la evolución de rasgos que no sirven a la supervivencia de su poseedor (ni del grupo o la especie, ver categoría seis). Este hecho entra en contradicción con la concepción (2) popular según la cual lo que importa en la evolución es la supervivencia per se. Esta concepción está muy difundida y se evidencia en 
conocidas expresiones que pretenden resumir la teoría de Darwin, tales como "la supervivencia del más fuerte” o "del más apto”. Desde el punto de vista del MESN, por el contrario, "lo que importa” es el éxito reproductivo (contrapunto conceptual). Los rasgos que incrementan las probabilidades de sobrevivir se seleccionan porque es frecuente (ipero no necesario!) que ese incremento en la supervivencia se traduzca en una mayor descendencia (Futuyma, 2009). En rigor, lo que importa, es decir, lo que determina qué variante se selecciona es el efecto de la variante sobre el fitness o “aptitud darwiniana”. El fitness suele definirse como la contribución promedio de un alelo o genotipo a las siguientes generaciones (Futuyma, 2009) ${ }^{1}$. Los casos de selección sexual (en los cuales suelen seleccionarse variantes que reducen la probabilidad de supervivencia de su poseedor) nos permiten, entonces, discutir con los estudiantes que lo importante en la evolución por selección natural es el impacto de las diferentes variantes de un rasgo en el éxito reproductivo y no en la supervivencia per se.

Categoría 3. Origen de un rasgo morfológico o fisiológico complejo que implica una ventaja en relación con la supervivencia del individuo

Aquí, “complejo" se refiere a rasgos formados por diversas partes que actúan coordinadamente en sentido funcional-adaptativo, como, por ejemplo, los ojos de los vertebrados o las alas de las aves. La evolución de estos rasgos ha supuesto un desafío para la teoría de la evolución desde los tiempos de Darwin (Darwin, 2010; Lenski et al., 2003). Esta complejidad hace que sea probabilísticamente imposible que un único cambio genético genere la versión actual del rasgo a partir del estado ancestral. Se trata, por el contrario, de rasgos que solo pueden explicarse por la selección acumulativa de varios cambios genéticos, frecuentemente con diferentes funciones implicadas en la selección de uno u otro cambio genético (contrapunto conceptual) (Dawkins, 2015). Esta noción choca con la concepción (3) de los estudiantes que, habiendo construido una primera versión elemental del MESN, tienden a pensar que todos los casos de evolución se explican en términos de una única mutación y su posterior selección (asociada a la función actual del rasgo). Estos casos tienen también el interés de poner en discusión la verosimilitud de que un único cambio genético produzca una estructura compleja y funcional. Esto es interesante porque en esta concepción errónea se basa un argumento falaz del movimiento creacionista según el cual el "puro azar” no podría jamás producir un rasgo como el ojo de los vertebrados. En cambio, desde el punto de vista del MESN, el origen de estos rasgos no se produce por "puro azar" porque la selección misma constituye un proceso no aleatorio (Dawkins, 2009a, 2009b, 2015).

\section{Categoría 4. Reducción o pérdida de un rasgo morfológico o fisiológico (evolución regresiva)}

Estos casos no tienen, en principio, nada de especial desde el punto de vista teórico, aunque a los propios científicos les resulta especialmente complicado explicarlos (Espinasa y Espinasa, 2008; Ha y Nehm, 2013). Desde el punto de vista didáctico, lo interesante es que se trata de ejemplos que cuestionan varias concepciones de los estudiantes. Según la primera de estas concepciones (4a) tener un rasgo siempre es ventajoso en comparación con no tenerlo. Una variante de esta concepción supone que (4b) siempre es mejor ser más grande, más veloz, más fuerte, etc.: "cuanto más mejor". Sin embargo, de acuerdo con el contrapunto conceptual, todo rasgo supone siempre ciertos costos, por lo que su eventual carácter ventajoso dependerá de un compromiso entre los costos y los beneficios (en términos de éxito reproductivo diferencial), lo que, a su vez, es relativo a la biología de la especie y a las condiciones ecológicas. Por estas razones, dadas ciertas condiciones, puede ser ventajoso ser más pequeño, más lento, menos fuerte o carecer de cierta

\footnotetext{
${ }^{1}$ Consideramos que, aunque menos rigurosa desde el punto de vista técnico, la noción de “éxito reproductivo” es una aceptable aproximación para la enseñanza básica.
} 
estructura. Vale decir, ningún rasgo es intrínsecamente ventajoso. Una tercera concepción que surge en la discusión de estos casos, que llamamos "compensación”, supone que (4c) la pérdida o reducción de una estructura ocurre para permitir la posterior adquisición de otro rasgo más ventajoso (González Galli y Meinardi, 2017). Así, es típico que los estudiantes propongan que los peces de cavernas perdieron la vista (Cuadro 1) para mejorar otro sentido, por ejemplo, el tacto, más útil en su medio ambiente oscuro. Esta idea supone otra según la cual (4d) la evolución implica previsión, pero la selección no supone ninguna forma de previsión y solo puede incrementar la frecuencia de aquellas variantes que resultan ventajosas "aquí y ahora”. Es posible que esta idea de compensación ayude a reducir la disonancia cognitiva generada por la (aparente) paradoja que supone perder algo que -desde la perspectiva del estudiante- es intrínsecamente bueno. Por otro lado, esta idea de compensación es superficialmente análoga a una hipótesis científica vigente para explicar algunos de estos casos basada en la noción de ligamiento genético (Espinasa y Espinada, 2008). Sin embargo, las explicaciones de los estudiantes nunca implican referencias explícitas al ligamiento genético, por lo que pueden interpretarse como una noción intuitiva de compensación. El caso de la pérdida del sentido de la vista -ver Cuadro 1- es especialmente provocador para los estudiantes, probablemente por el gran valor que para los humanos tiene este sentido. También tienen mucho potencial para discusión los casos de la pérdida de la capacidad de volar en varios linajes de aves. Nuevamente, estos casos resultan intrigantes y, por lo tanto, motivadores para la discusión debido a las evidentes ventajas que otorga el vuelo y que dificultan apreciar los costos de dicha capacidad.

Categoría 5. Origen de un rasgo etológico que implica una ventaja en relación con la supervivencia del individuo

Estos casos se diferencian de los demás porque el rasgo cuya evolución se pone en discusión es etológico. Este caso resulta problemático porque, aunque los estudiantes tienden a asociar fácilmente las variaciones morfo-fisiológicas con las diferencias genéticas, no consideran plausible que dichas diferencias influyan del mismo modo en las variaciones comportamentales. Así, según la concepción (5a) la morfología y la fisiología están influidas por los genes, pero el comportamiento no (tampoco la psiquis, la mente o la personalidad). Sin embargo, desde la biología actual, el comportamiento de los animales es parte del fenotipo y, por lo tanto, su desarrollo obedece a la interacción de factores genéticos y ambientales (Davies, Krebs y West, 2012; Plomin et al., 2002). Según otra concepción, relacionada y coherente con la anterior, (5b) el comportamiento solo se modifica mediante experiencias de aprendizaje o decisiones conscientes y voluntarias. Sin embargo, si el comportamiento está influido por los genes, entonces, también puede evolucionar por selección natural (Davies, Krebs y West, 2012). Creemos que cabe referirse a este modo de pensar como “dualista”, en el sentido de que asume la existencia de dos categorías claramente diferenciadas de rasgos, con supuestos causales asociados también diferentes (Pinker, 2003): por un lado, lo físico respondería a la influencia genética y, por otro, lo comportamental (psíquico, mental, espiritual), solo respondería a factores ambientales. Se trata de una concepción muy difundida (Ridley, 2003). Es probable que, además, opere aquí una analogía con el caso humano. En nuestra especie es notoria la flexibilidad conductual mediada por el aprendizaje y también la capacidad de modificar la conducta de un modo intencional y voluntario (Pozo, 2014). Así, en base a un razonamiento analógico-antropomórfico, los estudiantes responden, por ejemplo, para el caso presentado aquí (Cuadro 1), en términos de que "los monos se dieron cuenta de que de noche había menos depredadores y entonces decidieron cambiar sus hábitos" o "aprendieron a moverse de noche para no ser vistos por sus depredadores". Desde ya, no estamos diciendo que los animales no puedan modificar sus pautas de comportamiento mediante el aprendizaje, sino que estamos señalando que esos comportamientos también pueden modificarse por mutaciones y selección y que, sin embargo, esta última explicación no resulta, en general, concebible para los estudiantes. 
Categoría 6. Origen de un rasgo etológico que no implica una ventaja en relación con la supervivencia del individuo ("altruismo")

A las dificultades asociadas al caso anterior, esta categoría presenta la complicación agregada de que no resulta evidente cuál es la ventaja del rasgo etológico analizado. De hecho, el rasgo es perjudicial para su poseedor. Así, en el caso presentado en la Cuadro 1, al emitir la vocalización el individuo aumenta las probabilidades de llamar la atención del depredador sobre sí mismo. Al mismo tiempo, esa acción es ventajosa para los compañeros de grupo de quien emite la llamada. Así, aunque no es fácil imaginar que el rasgo en cuestión implique una ventaja para el individuo sí resulta fácil imaginar que supone una ventaja para el grupo o la especie. Los estudiantes recurren en este caso a la concepción según la cual (6) se seleccionan aquellas variantes que contribuyen a "la supervivencia de la especie”.

En etología, una conducta que reduce el éxito reproductivo de quien la ejecuta y al mismo tiempo incrementa el de otro individuo se llama “altruista” (Davies, Krebs y West, 2012). Desde una perspectiva darwiniana ortodoxa estos casos se explican recurriendo a dos hipótesis específicas (contrapunto conceptual): selección por parentesco y altruismo recíproco. La idea de selección por parentesco propone que la conducta altruista incrementa su frecuencia en la población -a pesar de perjudicar a su poseedor- porque su efecto está dirigido especialmente a parientes cercanos. Estos se parecen genéticamente al altruista, por lo que es probable que contengan también copias de los genes que predisponen a la conducta altruista. Si el efecto (en términos de fitness) positivo sobre los parientes supera al efecto negativo sobre el propio altruista, entonces, el rasgo incrementará su frecuencia en la población. Nótese que la entidad "beneficiada" no es el individuo sino los genes que lo predisponen a realizar esa conducta. Por eso, esta hipótesis se ha popularizado como "teoría del gen egoísta” (Davies Krebs y West, 2012; Dawkins, 2017). De acuerdo con la hipótesis del altruismo recíproco, estas conductas se seleccionan porque el individuo que en un momento actúa como altruista en otro momento recibe la "devolución del favor", de modo que obtiene un beneficio neto de esas interacciones (Davies Krebs y West, 2012; Dawkins, 2017). Una tercera hipótesis -más polémica- que en principio podría explicar la evolución de estas conductas altruista es la llamada selección de grupos. De acuerdo con esta idea, esas conductas se imponen en la población como resultado de un proceso de supervivencia y reproducción diferencial de grupos (y no de individuos como en la versión clásica del MESN). Se sugiere que los grupos formados por individuos altruistas tienen más probabilidades de sobrevivir, y por lo tanto de agrandarse y dar lugar a nuevos grupos derivados, que los grupos formados por individuos egoístas. Esta hipótesis tuvo mucha aceptación en la década de 1960, pero luego recibió una fuerte crítica (Williams, 1966) a partir de la cual cayó prácticamente en el olvido. En la década de 1990, sin embargo, algunos autores (Sober y Wilson, 2000; Wilson y Wilson, 2009) recuperaron la hipótesis de la selección de grupos. Pero aún ellos reconocen que deben darse condiciones muy especiales para que la selección de grupos sea una fuerza evolutiva importante. Aunque el tema (el "problema de los niveles o unidades de selección”) es aún hoy objeto de debate (Ayala y Arp, 2010), la mayoría de los expertos cree que la selección por parentesco y el altruismo recíproco explican satisfactoriamente la mayoría de los casos conocidos de altruismo (Davies, Krebs y West, 2012). En relación con las concepciones de los estudiantes, suele suceder que, al no ver la ventaja para el individuo, pero sí la posible ventaja para el grupo, creen haber resuelto el caso sin percibir la incompatibilidad de tal explicación con el MESN. Así, dan por explicados estos casos afirmando que el rasgo evolucionó por servir a "la supervivencia de la especie” (González Galli y Meinardi, 2017). En general, los razonamientos en términos de "el bien del grupo" están muy difundidos entre los no expertos (Pinker, 2002). Es importante señalar que no se trata de que estos estudiantes estén aplicando conscientemente la hipótesis de selección de grupos, sino que están asumiendo acríticamente que el rasgo será seleccionado siempre que implique una ventaja para alguien o algo, sin importar cuál sea la entidad beneficiada por esa ventaja. Otra evidencia de la presencia de este supuesto es la popularidad de la 
hipótesis de Gaia, de acuerdo con la cual los rasgos que observamos evolucionaron porque son beneficiosos para el planeta todo (Dawkins, 2000). Así, este caso permite poner en discusión el problema de los niveles o unidades de selección. Se trata de un tema muy complejo, por lo que su tratamiento podría ser muy difícil en el nivel de la escuela secundaria. Sin embargo, sería deseable su abordaje en la formación del profesorado de biología.

CUADRO 1. Ejemplos de casos-problema para cada categoría

\begin{tabular}{|c|c|}
\hline Categoría & Ejemplo de pregunta-problema basada en un caso concreto \\
\hline 1 & $\begin{array}{l}\text { Las membranas interdigitales de los patos. Los patos son aves acuáticas que } \\
\text { tienen una membrana entre los dedos de sus patas. Supongan que los patos } \\
\text { actuales descienden evolutivamente de una población de patos que, generaciones } \\
\text { atrás, no tenían membranas entre los dedos de sus patas ¿Cómo podrían explicar } \\
\text { cómo o por qué una antigua población cuyos individuos típicos no tenían esas } \\
\text { membranas dio lugar, generaciones después, a una población formada } \\
\text { principalmente por individuos típicos con membranas? }\end{array}$ \\
\hline 2 & $\begin{array}{l}\text { La cola del pavo real. Supongan que los actuales pavos reales descienden } \\
\text { evolutivamente de una población de pavos en la que, típicamente, tanto machos } \\
\text { como hembras tenían colas pequeñas y poco llamativas ¿Cómo podrían explicar } \\
\text { cómo o por qué una antigua población cuyos individuos típicos tenían este } \\
\text { aspecto dio lugar, generaciones después, a una población formada principalmente } \\
\text { por machos con grandes colas coloridas? }\end{array}$ \\
\hline 3 & $\begin{array}{l}\text { Las alas de las aves. Supongan que las actuales aves descienden evolutivamente } \\
\text { de una población de dinosaurios que, típicamente, tenían miembros anteriores en } \\
\text { forma de «brazos» ¿Cómo podrían explicar cómo o por qué una antigua } \\
\text { población cuyos individuos típicos tenían este aspecto dio lugar, generaciones } \\
\text { después, a una población formada principalmente por individuos con grandes } \\
\text { alas que permiten el vuelo? }\end{array}$ \\
\hline 4 & $\begin{array}{l}\text { La ceguera de los peces cavernícolas. En ríos subterráneos donde no llega nada } \\
\text { de luz existen peces que no tienen ojos. Supongan que estas poblaciones de peces } \\
\text { ciegos derivan evolutivamente de poblaciones de peces formadas por individuos } \\
\text { típicos con ojos y visión ¿Cómo podrían explicar cómo o por qué una antigua } \\
\text { población cuyos individuos típicos tenían ojos y una buena visión dio lugar, } \\
\text { generaciones después, a una población formada principalmente por individuos } \\
\text { ciegos? }\end{array}$ \\
\hline 5 & $\begin{array}{l}\text { La nocturnidad del "mono lechuza". El "mono lechuza" es un mono que habita } \\
\text { las selvas del norte de Argentina y es uno de los pocos monos de hábitos } \\
\text { nocturnos. Suponiendo que su ancestro evolutivo era diurno. ¿Cómo podrían } \\
\text { explicar cómo o por qué una antigua población de monos de hábitos } \\
\text { principalmente diurnos dio origen, generaciones después, a una población } \\
\text { formada por individuos típicos de hábitos principalmente nocturnos? }\end{array}$ \\
\hline 6 & $\begin{array}{l}\text { Las "llamadas de alarma” en las ardillas de tierra. Las ardillas de tierra son unos } \\
\text { roedores que viven en grupos numerosos en madrigueras subterráneas. Cuando } \\
\text { están alimentándose fuera de sus madrigueras y aparece un depredador como un } \\
\text { águila es frecuente que algún individuo se pare sobre sus patas traseras y emita } \\
\text { un fuerte sonido que sirve de alarma al resto de los integrantes del grupo que } \\
\text { huyen rápidamente a esconderse en sus madrigueras. ¿Cómo podrían explicar } \\
\text { cómo o por qué una antigua población de ardillas en las que no contaban con esta } \\
\text { conducta dio origen, generaciones después, a una población formada por } \\
\text { individuos que emiten estas "llamadas de alarma”? }\end{array}$ \\
\hline
\end{tabular}

Fuente: elaboración propia 


\section{OBSTÁCULOS SUBYACENTES}

Muchas de las concepciones que mencionamos pueden interpretarse como expresiones específicas de algunas formas de razonar más generales que llamamos obstáculos epistemológicos. En el Cuadro 2 mostramos algunos posibles obstáculos subyacentes a algunas de las concepciones más comunes sobre evolución y el correspondiente contrapunto conceptual.

CUADRO 2. Obstáculos epistemológicos, contrapunto conceptual y algunas concepciones sobre evolución biológica relacionadas

\begin{tabular}{|c|c|c|c|}
\hline Obstáculo & Breve definición & Contrapunto conceptual & $\begin{array}{l}\text { Concepciones } \\
\text { relacionadas }\end{array}$ \\
\hline $\begin{array}{l}\text { Teleología de } \\
\text { sentido común } \\
\text { (TSC) }\end{array}$ & $\begin{array}{l}\text { Todos los procesos y } \\
\text { estructuras biológicas } \\
\text { responden a un fin } \\
\text { (frecuentemente la } \\
\text { supervivencia). }\end{array}$ & $\begin{array}{llr}\text { Todos los } & \text { procesos y } \\
\text { estructuras } & \text { biológicas } \\
\text { responden } & \text { a } & \text { causas } \\
\text { eficientes } & \text { que } & \text { los } \\
\text { preceden. } & & \end{array}$ & 1a, 1b, 1c. \\
\hline $\begin{array}{l}\text { Razonamiento } \\
\text { centrado en el } \\
\text { individuo (RCI) }\end{array}$ & $\begin{array}{l}\text { Los cambios } \\
\text { evolutivos se reducen } \\
\text { a y son el resultado de } \\
\text { la sumatoria de los } \\
\text { cambios sufridos por } \\
\text { cada individuo. }\end{array}$ & $\begin{array}{l}\text { Los cambios evolutivos } \\
\text { son consecuencia de un } \\
\text { cambio en la } \\
\text { composición de la } \\
\text { población. }\end{array}$ & 1a, 1b, 1c. \\
\hline $\begin{array}{l}\text { Razonamiento } \\
\text { causal lineal } \\
\text { (RCL) }\end{array}$ & $\begin{array}{l}\text { Todo fenómeno } \\
\text { natural tiene una causa } \\
\text { única que lo precede. }\end{array}$ & \begin{tabular}{lr} 
Los & \multicolumn{2}{r}{ fenómenos } \\
naturales suelen tener \\
varias & causas \\
concurrentes &
\end{tabular} & 5a, 5b. \\
\hline $\begin{array}{l}\text { Esencialismo de } \\
\text { sentido común } \\
\text { (ESC) }\end{array}$ & $\begin{array}{l}\text { Cada individuo } \\
\text { pertenece a una } \\
\text { categoría definida por } \\
\text { un conjunto de rasgos } \\
\text { inmutables que } \\
\text { constituyen su esencia. }\end{array}$ & 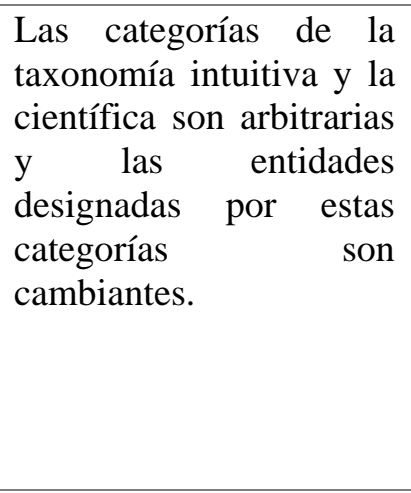 & $\begin{array}{lr}\text { Las concepciones } \\
\text { relacionadas con este } \\
\text { obstáculo r se } \\
\text { expresan } \\
\text { claramente cuando se } \\
\text { analiza el } \\
\text { nuevas } & \text { origen de } \\
\text { problema } & \text { especies, } \\
\text { abordado en los } \\
\text { casos nos } \\
\text { propuestos. }\end{array}$ \\
\hline $\begin{array}{l}\text { Determinismo } \\
\text { (D) }\end{array}$ & $\begin{array}{l}\text { El estado actual de un } \\
\text { sistema determina su } \\
\text { estado futuro, no se } \\
\text { asignan probabilidades } \\
\text { a los posibles estados } \\
\text { futuros alternativos. }\end{array}$ & $\begin{array}{l}\text { Dado un estado actual } \\
\text { de un sistema existen } \\
\text { diversos posibles } \\
\text { estados futuros a cada } \\
\text { uno de los cuales se le } \\
\text { puede asignar una } \\
\text { probabilidad } \\
\text { ocurrencia. }\end{array}$ & 1a, 1b, 1c. \\
\hline $\begin{array}{l}\text { Progresividad } \\
\text { de sentido } \\
\text { común (PSC) }\end{array}$ & $\begin{array}{l}\text { Todos los cambios } \\
\text { biológicos implican } \\
\text { una mejora en } \\
\text { términos absolutos. }\end{array}$ & $\begin{array}{l}\text { No se puede considerar } \\
\text { los cambios en los } \\
\text { sistemas biológicos } \\
\text { como progresivos } \\
\text { porque no se los puede } \\
\text { considerar positivos en } \\
\text { términos absolutos. }\end{array}$ & 4a, 4b, 4c, 4d. \\
\hline
\end{tabular}




\begin{tabular}{|c|c|c|c|}
\hline Antropomorfismo & $\begin{array}{l}\text { Los organismos no } \\
\text { humanos (e incluso } \\
\text { entidades no vivas) } \\
\text { naturales son como los } \\
\text { humanos. }\end{array}$ & \begin{tabular}{llr}
\multicolumn{3}{l}{ Solo algunos rasgos son } \\
compartidos por & los \\
humanos y y & los \\
organismos no humanos.
\end{tabular} & 5a, 5b. \\
\hline Vitalismo & $\begin{array}{l}\text { Los fenómenos } \\
\text { biológicos } \\
\text { causados y guiados por } \\
\text { una fuerza vital. }\end{array}$ & $\begin{array}{lr}\text { Los } & \text { fenómenos } \\
\text { biológicos } & \text { están } \\
\text { causados por procesos } \\
\text { físico-químicos. }\end{array}$ & 1a, 1b, 1c. \\
\hline
\end{tabular}

Fuente: elaboración propia

Por cuestiones de espacio, no analizaremos todas las posibles relaciones entre las concepciones y los obstáculos, sino que nos limitaremos a señalar algunas de dichas relaciones con el objetivo de ilustrar el potencial de este tipo de análisis. Tomando el que tal vez sea el caso más evidente, las concepciones 1a, 1b y 1c pueden interpretarse fácilmente como expresiones de la TSC. Este caso ha sido analizado in extenso en otros trabajos (González Galli y Meinardi, 2017, 2015, 2011), por lo que a continuación comentaremos otros ejemplos. Solo señalaremos que el problema de estas concepciones no en sí que supongan un razonamiento teleológico, ya que existen fuertes razones para afirmar que los propios biólogos recurren a estos razonamientos (Caponi, 2003; González Galli, 2016; Ruse, 2000). Sin embargo, el biólogo, a diferencia del no experto, comprende el significado preciso y el alcance de esos razonamientos y expresiones, que pueden interpretase como metafóricos (Ruse, 2000). Por ejemplo, el razonamiento del biólogo no implicará supuestos intencionales, mientras que en el caso del no experto dichos supuestos pueden estar presentes (Carey, 1995; Sinatra, Brem y Evans, 2008).

Las concepciones 4a, 4b, 4c y 4d, por su parte, pueden considerarse una expresión del obstáculo "progresividad de sentido común” (Cuadro 2) (Johnson, Lahti y Blumstein, 2012; Werth, 2012). En efecto, si el estudiante cree que la evolución implica un progreso y al mismo tiempo considera que siempre es mejor tener y tener más, entonces, solo podrá explicar la pérdida o reducción de algo como una condición para la adquisición de algo mejor aún. Gelman y Rhodes (2012) sugieren que el esencialismo (“esencialismo de sentido común”, Cuadro 2) también favorecería una concepción progresiva de la evolución.

En relación con la categoría 5, hemos sugerido que la idea de que el comportamiento animal en general solo responde a causas ambientales podría considerare una expresión del obstáculo que denominamos "antropomórfico" (Cuadro 2). También hemos sugerido que podría subyacer un supuesto dualista que, por su gran alcance, también podría considerase como un obstáculo en sí mismo. Estas concepciones (5a y 5b) también pueden considerarse una expresión del RCL (Cuadro 2) ya que reducen la explicación a un único tipo de causa (ambiental) cuando, desde el punto de vista científico, la conducta -como todo rasgo biológico- depende de la interacción entre causas genéticas y ambientales.

\section{DISCUSIÓN Y CONCLUSIONES}

En este trabajo asumimos que la explicitación y revisión crítica de las concepciones y obstáculos analizados es una condición necesaria para la construcción de modelos más cercanos al MESN. También creemos útil analizar estas concepciones en términos de los obstáculos subyacentes, análisis que facilita un tratamiento transversal que va más allá de los errores "locales” (González Galli y Meinardi, 2016; Peterfalvi, 2001). Así, por ejemplo, la comprensión de que tanto la idea de que las crías "nacen adaptadas" (cuando se trata el tema evolución) como la idea de que una célula "apaga" un gen "cuando no necesita" su producto (cuando se trata el tema biología celular y molecular) son la expresión de un mismo supuesto (“teleología de sentido común”, Cuadro 2) contribuye a la identificación y regulación consciente del obstáculo subyacente. Ofrecimos una 
tipología de casos de complejidad creciente que se puede tener en cuenta en el diseño de la enseñanza del MESN. No sugerimos, sin embargo, que estos casos deban ser tratados necesariamente en un orden lineal. Esta advertencia se debe a lo mencionado en la sección 2 sobre la dependencia de la complejidad en relación con los conocimientos de los estudiantes. Por ejemplo, por razones idiosincráticas, un grupo de estudiantes podría estar muy familiarizado con los ejemplos de selección sexual (categoría 2), en cuyo caso dichos casos podrían resultar no más complejos que los de la categoría 1. Creemos, sin embargo, que estas situaciones serán más bien excepcionales y que, en general, los estudiantes encontrarán una dificultad creciente para aplicar el MESN que se corresponde aproximadamente con el orden de las categorías aquí definidas. En cualquier caso, nuestra intención no es ofrecer una secuencia didáctica concreta sino más bien poner en evidencia las concepciones, los obstáculos y la complejidad asociados a cada tipo de caso, de modo que el docente que diseñe una progresión del aprendizaje para una población concreta de estudiantes pueda tomar como insumo esta categorización. El criterio (basado en la explicitación y revisión de concepciones y obstáculos) para la selección de casos aquí propuesto no es excluyente ni incompatible con otros posibles criterios. Por ejemplo, sería deseable abordar casos de evolución vegetal, ya que la biología intuitiva de los estudiantes no atribuye necesariamente a las plantas las mismas propiedades biológicas que a los animales (Stavy y Wax, 1989; Leddon, Waxman y Medin, 2008). Más específicamente, algunos estudios sugieren que los estudiantes utilizan menos ideas clave de la teoría evolutiva cuando analizan casos de evolución vegetal que cuando se trata de evolución animal (Heredia, Furtak y Morrison 2016; Opfer, Nehm y Ha, 2012). También está plenamente justificada la introducción de casos de evolución humana. En relación con este tema, hemos sugerido en otro trabajo (González Galli y Pérez, 2016) la utilidad de abordar tópicos relacionados con la llamada "medicina darwiniana" (Jenkins y Antolin, 2011; Nesse y Williams, 2000), que aportan una perspectiva de análisis original desde las llamadas “causas últimas" o evolutivas (Mayr, 2006) a la comprensión de los problemas de salud. En relación con tener en cuenta otros criterios, debemos señalar que no cabe esperar que el tratamiento de un caso resulte en la superación definitiva de los obstáculos implicados. En este sentido, tener en cuenta otros criterios, como los mencionados más arriba, puede permitir volver al análisis de los mismos obstáculos. De hecho, se requiere un trabajo continuo de este tipo para el desarrollo de la “vigilancia metacognitiva”. Así, por ejemplo, el caso de la pérdida de estructuras (categoría 4) se podría tratar a partir del ejemplo de los peces ciegos, pero también sería deseable discutirlo a partir del caso del apéndice humano. Finalmente, cabe destacar que aquí hablamos de "categorías” porque no proponemos casos concretos (los mostrados en la Cuadro 1 son solo ejemplos posibles) sino criterios para la selección de dichos casos. Así, para cualquiera de las categorías el problema concreto podría decidirse en base a otros criterios o factores de contexto que hagan más relevantes ciertos casos. Por último, insistimos en que, dado el carácter contextual de toda situación didáctica, esta propuesta debe entenderse como hipotética, lo que implica que los docentes deben estar atentos a la aparición de concepciones y obstáculos que no hemos identificado en este trabajo. Sin embargo, la investigación disponible nos permite pensar que es alta la probabilidad de que encontremos en nuestras clases ideas semejantes a las que aquí analizamos y que, por lo tanto, el trabajo a partir de estos casos contribuya al aprendizaje del MESN.

\section{Referencias}

Astolfi, J. (2002). Aprender en la escuela. Santiago de Chile: Dolmen.

Astolfi, J. (2001). Conceptos clave en la didáctica de las disciplinas. Sevilla: Díada.

Astolfi, J. (1999). El “error” un medio para enseñar. Sevilla: Díada.

Ayala, F. y Arp, R. (Eds.) (2010). Contemporary Debates in Philosophy of Biology. Malden: Wiley-Blackwell. 
Bardapurkar, A. (2008). Do Students See "Selection” in Organic Evolution? A Critical Review of the Causal Structure of Student Explanations. Evolution Education and Outreach, 1(3), 299305. DOI: $10.1007 / \mathrm{s} 12052-008-0048-5$

Bishop, B. y Anderson, C. (1990). Students conceptions of natural selection and its role in evolution. Journal of Research in Science Teaching, 27(5), 415-427. DOI: 10.1002/tea.3660270503.

Campanario J. (2000). El desarrollo de la metacognición en el aprendizaje de las ciencias: estrategias para el profesor y actividades orientadas al alumno. Enseñanza de las ciencias: revista de investigación y experiencias didácticas, 18(3), 369-380.

Camilloni, A. (ed.). (2001). Los obstáculos epistemológicos en la enseñanza. Barcelona: Gedisa.

Caponi, G. (2003). Darwin: entre Paley y Demócrito. História, Ciências, Saúde. Manguinhos, 10(3), 993-1023. DOI: 10.1590/S0104-59702003000300010

Carey, S. (1995). On the origin of causal understanding. En Sperber, D., Premak, D. y Premak, A. (eds.). Causal Cognition: A Multidisciplinary Debate (pp. 268-308). New York: Oxford University Press.

Darwin, C. (2010). El origen de las especies por medio de la selección natural. Madrid: Alianza.

Davies, N., Krebs, J. y West, S. (2010). An Introduction to Behavioural Ecology. Oxford: WileyBlackwell.

Dawkins, R. (2000). Destejiendo al arco iris. Ciencia, ilusión y el deseo de asombro. Barcelona: Tusquets.

Dawkins, R. (2009a). Evolución. El mayor espectáculo sobre la Tierra. Madrid: Espasa Calpe.

Dawkins, R. (2009b). El espejismo de Dios. Madrid: Espasa Calpe.

Dawkins, R. (2015). El relojero ciego. Por qué la evolución de la vida no necesita de ningún creador. Barcelona: Tusquets.

Dawkins, R. (2017). El gen egoísta extendido. Madrid: Salvat.

De Vecchi, G y Giordan, a. (2006). Guía práctica para la enseñanza científica. Sevilla: Díada.

Dupré, J. (2006). El legado de Darwin. Qué significa hoy la evolución. Buenos Aires: Katz.

Espinasa, M. y Espinasa, L (2008). Losing Sight of Regressive Evolution. Evolution: Education and Outreach, 1(4), 509-516. DOI: 10.1007/s12052-008-0094-z

Fourez, G. (2005). Alfabetización científica y tecnológica. Acerca de las finalidades de la enseñanza de las ciencias. Buenos Aires: Colihue.

Futuyma, D. (2009). Evolution. Sunderland: Sinauer.

Gelman, S. y Rhodes, M. (2012). “Two Thousand Years of Stasis”. How Psychological Essentialism Impedes Evolutionary Understanding. En K. Rosengren; S. Brem, E. Evans y G. Sinatra (eds.), Evolution challenges. Integrating research and practice in teaching and learning about evolution (pp. 3-21). Oxford: Oxford University Press.

García, D. (1994). El conocimiento escolar como proceso evolutivo: aplicación al conocimiento de nociones ecológicas. Investigación en la Escuela, 23, 65-76.

Gómez, A. (2009). El estudio de los seres vivos en la educación básica. Enseñanza del sistema nervioso desde un enfoque para la evolución de los modelos escolares. Monterrey: Tendencias - Universidad Autónoma de Nuevo León.

González Galli, L. (2016). El problema de la teleología y la metáfora del diseño en biología: cuestiones epistemológicas e implicancias didácticas. TED (Tecné, Episteme y Didaxis), 40. DOI: $\underline{10.17227 / 01203916.6151}$

González Galli, L. y Meinardi, E. (2017). Obstáculos para el aprendizaje del modelo de evolución por selección natural en estudiantes universitarios de biología. Revista Eureka sobre Enseñanza y Divulgación de las Ciencias, 14(3), 435-449.

González Galli, L. y Meinardi, E. (2016). Obstáculos para el aprendizaje del modelo de evolución por selección natural. En N. Cuvi, E. Servilla, R. Ruiz y M. Puig Samper (eds.), Evolucionismo en América y Europa. Antropología, Biología, Política y Educación (pp. 463- 
476). Quito: Ediciones Doce Calles - FLACSO Ecuador - Universidad Autónoma de México - Pontificia Universidad Católica de Ecuador.

González Galli, L. y Meinardi, E. (2015). Obstáculos para el aprendizaje del modelo de evolución por selección natural en estudiantes de escuela secundaria de Argentina. Ciencia y Educação, 21(1), 101-122. DOI: 10.1590/1516-731320150010007

González Galli, L. y Meinardi, E. (2013). ¿Está en crisis el darwinismo? Los nuevos modelos de la biología evolutiva y sus implicaciones didácticas. Didáctica de las Ciencias Experimentales y Sociales, 27, 219-234. DOI: 10.7203/dces.27.2458

González Galli, L. y Meinardi, E. (2011). The Role of Teleological Thinking inLearning the DarwinianModel of Evolution.Evolution Education \& Outreach, 4, 145-152. DOI: 10.1007/s12052-010-0272-7

González Galli, L. y Pérez G. (2016). Cómo convertir a la teoría de la evolución en un eje transversal para la enseñanza de la biología. En G. Abruzzese e I. Soto (comps.), A la luz de la evolución. Jornada de Biología Evolutiva 2016. Buenos Aires: Ignacio María Soto.

Ha, M. y Nehm, R. (2013). Darwin's Difficulties and Students' Struggles with Trait Loss: Cognitive-Historical Parallelisms in Evolutionary Explanation. Science \& Education, 23(5), 1051-1074. DOI: 10.1007/s11191-013-9626-1

Heredia, S., Furtak, E. y Morrison, D. (2016). Exploring the influence of plant and animal item contexts on student response patterns to natural selection multiple choice items. Evolution Education \& Outreach, 9(10). DOI: 10.1186/s12052-016-0061-z

Jenkins, K y Antolin, M. (2011). Evolution and medicine. Evolution Education \& Outreach, 4, 556558. DOI: $10.1007 / \mathrm{s} 12052-011-0375-9$.

Jiménez, M. (1993). Darwinian and Lamarckian Models Used by Students and Their Representation. En K. Fisher y M. Kibby (Eds.), Knowledge Acquisition, Organization, and Use in Biology. Berlín: Springer.

Jiménez, M. (1991). Cambiando las ideas sobre el cambio biológico. Enseñanza de las ciencias: revista de investigación y experiencias didácticas, 9(3), 248-256.

Johnson, N. Lahti, D. y Blumstein, D. (2012). Combating the Assumption of Evolutionary Progress: Lessons from the Decay and Loss of Traits.Evolution: Education and Outreach, 5, 128-138. DOI: 10.1007/s12052-011-0381:y

Kalinowski, S., Leonard, M., Andrews, T. y Litt, A. (2013). Six Classroom Exercises to Teach Natural Selection to Undergraduate Biology Students.CBE—Life Sciences Education, 12(3), 483-493. DOI: $10.1187 / \mathrm{cbe}-12-06-0070$

Kampourakis, K. (2014). Understanding evolution. Cambridge: Cambridge University Press.

Leddon, E., Waxman, S. y Medin, D. (2008). Unmasking “alive:” children's appreciation of a concept linking all living things. Cognitive Development, 9(4), 461-473. DOI:10.1080/15248370802678463.

Lenski, R., Ofria, C., Pennock, R. y Adami, C. (2003). The evolutionary origin of complex features. Nature, 423, 139-144. DOI: 10.1038/nature01568.

Mayr, E. (2006). Por qué es única la biología. Consideraciones sobre la autonomía de una disciplina científica. Buenos Aires: Katz.

Meinardi, E. (2010). Educar en ciencias. Buenos Aires: Paidós.

Nesse, R. y Williams, G. (2000). ¿Por qué enfermamos? Barcelona: Grijalbo.

Opfer, J., Nehm, R. y Ha, M. (2012). Cognitive foundations for science assessment design: knowing what students know about evolution. Journal of Research in Science Teaching, 49(6), 744-77. DOI: 10.1002/tea.21028.

Peterfalvi, B. (2001). Identificación de los obstáculos por parte de los alumnos. En A. Camilloni (Ed.), Los obstáculos epistemológicos en la enseñanza (pp. 127-168). Barcelona: Gedisa.

Pinker, S. (2002). Cómo funciona la mente. Buenos Aires: Planeta. 
Pinker, S. (2003). La tabla rasa. La negación moderna de la naturaleza humana. Barcelona: Paidós.

Plomin, R., Defries, J., Mcclearn, G. y Mcguffin, P. (2002). Genética de la conducta. Barcelona: Ariel.

Posner, G., Strike, K., Hewson, P. y Gertzog, W. (1988). Acomodación de un concepto científico: hacia una teoría del cambio conceptual. En Porlán, García y Cañal (eds.). Constructivismo y enseñanza de las ciencias (pp. 91-114). Sevilla: Díada.

Pozo, J. (2014). Psicología del aprendizaje humano. Adquisición de conocimiento y cambio personal. Madrid: Morata.

Ridley, M. (2003). Nature via nurture. Genes, Experience, and What Makes Us Human. Nueva York: Harper Collins Publishers.

Ruse, M. (2000). Teleology: Yesterday, Today, and Tomorrow? Studies in History and Philosophy of Biological \& Biomedical Sciences, 31(1), 213-232. DOI: 10.1016/S1369-8486(99)00046-1

Sanmartí, N. (2002). Didáctica de las ciencias en la educación secundaria obligatoria. Madrid: Síntesis.

Schnotz, W., Vosniadou, S. y Carretero, M. (2006). Cambio conceptual y educación. Buenos Aires: Aique.

Sinatra, G., Brem, S. y Evans, M. (2008). Changing Minds? Implications of Conceptual Change for Teaching and Learning about Biological Evolution.Evolution Education and Outreach, 1(2), 189-195. DOI: 10.1007/s12052-008-0037-8

Sober, E. y Wilson, D. (2000).El comportamiento altruista. Evolución y psicología. Madrid: Siglo XXI.

Stavy, R. y Wax, N. (1989).Children's Conceptions of Plants as Living Things. Human Development 32(2), 88-94. DOI: 10.1159/000276367

Strike, K. y Posner, G. (1992). A revisionist theory of conceptual change. En R. Duschl y R. Hamilton (eds.), Philosophy of Science, Cognitive Psychology, and Educational Theory and Practice (pp. 147-176). Albany: Suny.

Werth, A. (2012). Avoiding the pitfall of progress and associated perils of evolutionary education. Evolution: Education and Outreach, 5(2), 249-265. DOI: 10.1007/s12052-012-0417-y

Wilson, D. y Wilson, E. (2009). Evolución "por el bien del grupo”. Investigación y Ciencia, 388, 46-57.

Williams, G. (1966). Adaptation and natural selection; a critique of some current evolutionary thought. Princeton, N.J.: Princeton University Press.

White, P., Heidemann, M., Loh, M. y Smith, J. (2013). Integrative cases for teaching evolution.Evolution Education \& Outreach, 6(17). DOI: 10.1186/1936-6434-6-17

Zimmer, C. (2008). The Evolution of Extraordinary Eyes: The Cases of Falttfishes and Stalk-eyed Flies. Evolution Education \& Outreach, 6(17). DOI: 10.1007/s12052-008-0089-9

Zohar, A. y Dori, Y. (eds.). (2012). Metacognition in Science Education.Trends in Current Research. Dordretch: Springer.

CÓMO CITAR ESTE ARTÍCULO

González Galli, L., Meinardi, E., y Pérez, G. (2018). Una tipología de casos para enseñar el modelo de evolución por selección natural. Didáctica de las ciencias experimentales y sociales, 34, 77-90. DOI: 10.7203/DCES.34.12056. 